\title{
Anticonceptivos de larga acción y embarazo adolescente
}

\author{
Long-Acting Contraception and Teenage Pregnancy
}

Secura GM y col. N Engl J Med 2014;371(14):1316-23

\section{Objetivos}

Medir las tasas de embarazos, nacimientos y abortos en una cohorte de adolescentes facilitando el acceso a los anticonceptivos de larga acción (entre los que se incluyen los implantes y los dispositivos intrauterinos o DIU) y comparar los datos obtenidos con las cifras nacionales.

\section{Diseño y población}

Cohorte abierta prospectiva que incluyó 1.404 mujeres de entre 14 y 19 años residentes del área de Saint Louis, Estados Unidos. Los datos fueron obtenidos entre 2008 y 2013.

Se les brindó consejería acerca de los distintos métodos anticonceptivos de manera ordenada de mayor a menor efectividad, incluyendo información sobre los beneficios y los efectos adversos de cada uno. El mismo día, cada participante optó por el método de su preferencia, que fue brindado gratuitamente durante todo el período del estudio. Se realizó seguimiento telefónico cada tres meses el primer año y luego cada seis meses durante dos o tres años.

\section{Resultados principales}

El $71,5 \%$ de las pacientes de la cohorte eligió un método anticonceptivo reversible de larga acción (ARLA). El 50\% de las mujeres más jóvenes (14 a 17 años) optó por el implante subdérmico, mientras que el $35,4 \%$ de las de 18 a 19 años lo hizo por el DIU hormonal.
Las tasas de seguimiento al finalizar el primer, segundo y tercer año fueron 92,82 y $75 \%$, respectivamente.

Se observó una tasa de embarazos de 34,0 cada 1.000 adolescentes, en comparación con estimaciones nacionales de 57,4 embarazos cada 1.000 adolescentes y 158,5 cada 1.000 adolescentes sexualmente activas. Las tasas de nacimientos y abortos también fueron menores que las cifras nacionales. Se registraron 56 embarazos durante el seguimiento, de los cuales casi el $50 \%$ ocurrieron en las mujeres no estaban empleando ningún método anticonceptivo. No se registraron embarazos en las mujeres que usaban DIU de cobre o implante subdérmico.

\section{Conclusión}

Las adolescentes que recibieron anticonceptivos gratuitos y educación en relación a los beneficios de los ARLA alcanzaron tasas de embarazos, nacimientos y abortos menores que las cifras nacionales.

Fuente de financiamiento: Susan Thompson Buffett Foundation, Eunice Kennedy Shriver National Institute of Child Health and Human Development, National Center for Advancing Translational Sciences, National Institutes of Health. Conflictos de interés: Algunos autores reportaron honorarios como asesores de Bayer, Teva, MicroCHIPS, y Watson/Activis.

\section{Comentario}

El estudio presentado es de carácter meramente descriptivo, ya que no se lleva a cabo ninguna comparación estadística entre las tasas de eventos observadas en el estudio y aquellas de carácter nacional.

Algunas limitaciones del diseño consisten en que la tasa de embarazos fue calculada en base al autoreporte y que la adherencia a los métodos anticonceptivos pudo haber estado influenciada por el seguimiento telefónico. Además, el orden en que fue brindada la información sobre los métodos anticonceptivos pudo haber influenciado una mayor elección de los métodos de larga duración.

A pesar de las limitaciones señaladas, el contexto de cambios en salud pública en que se desarrolló este estudio contribuye a la relevancia de la discusión de la anticoncepción en la población adolescente. En el año 2010, el presidente de los Estados Unidos, Barack Obama, firmó la Ley de Cuidados de Salud Asequibles (en inglés Affordable Care Act) ${ }^{1}$ con el objetivo de dar acceso a los estadounidenses a seguros médicos de calidad de acuerdo a sus posibilidades económicas y reducir así el gasto público en salud.
En Septiembre de este año, la revista Pediatrics de la Academia Americana de Pediatría publicó una declaración política, en la que se expide a favor de que los métodos ARLA sean considerados de primera línea para las mujeres adolescentes (dada su eficacia, seguridad y facilidad de uso). Asimismo, señala la importancia de brindar la información de manera clara y ordenada, describiendo en primer lugar el método anticonceptivo más efectivo².

En Nuestro País, el Ministerio de Salud de la Nación, a través del Programa Nacional de Salud Sexual y Procreación Responsable comenzó a distribuir el implante subdérmico como método anticonceptivo en provincias seleccionadas ${ }^{3}$.

\section{Conclusiones del comentador}

Parte de nuestro rol como médicos de familia es aconsejar a las pacientes adolescentes sobre los distintos métodos anticonceptivos. Para eso debemos conocer las distintas opciones, incluyendo los métodos de larga acción, y adaptar nuestros conocimientos a las necesidades particulares de cada paciente adolescente.

María Emilia Espósito [ Servicio de Medicina Familiar y Comunitaria del Hospital Italiano de Buenos Aires. mariaemilia.esposito@ hospitalitaliano.org.ar ]

Esposito ME, Provisión De Anticonceptivos Gratuitos De Larga Acción Y Embarazo Adolescente. Evid Act Pract Amb. 2015;18(2):35. Abr-Jun. Comentado de: Secura GM, et al. Provision of no-cost, long-acting contraception and teenage pregnancy. NEJM. 2014;371(14):1316-23. PMID: 25271604

\section{Referencias:}

1. Affordable Care Act (en línea). U.S. Department of Health \& Human Services.

Disponible en: http://www.hhs.gov/healthcare/rights/law/index.html (último acceso junio 2015).

2. Ott MA, Sucato GS, Contraception for Adolescents. Pediatrics, 2014;134(4):e1244-1256.

3. Ministerio de Salud de la Nación presenta nuevo anticonceptivo destinado a adolescentes (en línea). Ministerio de Salud de la Nación. Disponible en: http://www.msal.gov.ar/prensa/index.php/articulos/lista-de-slide-de-destacados/2110-ministerio-de-salud-de-la-nacion-presenta-nuevo-anticonceptivo-destinado-a-adolescentes (último acceso junio 2015). 